\title{
Two Decades of STEM Education Research in Middle School: A Bibliometrics Analysis in Scopus Database (2000-2020)
}

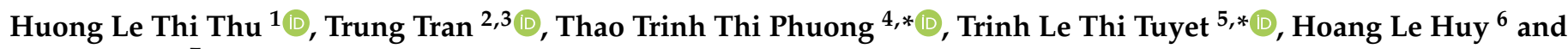 \\ Thuy Vu Thi ${ }^{7}$
}

1 Primary Education Department, Thai Nguyen University of Education, Thai Nguyen 250000, Vietnam; lethithuhuong@tnue.edu.vn

2 Vietnam Academy for Ethnic Minorities, Hanoi 100000, Vietnam; trungt1978@gmail.com

3 VNU, University of Education, Vietnam National University, Hanoi 100000, Vietnam

4 Faculty of Mathematics, Thai Nguyen University of Education, Thai Nguyen 250000, Vietnam

5 Elementary Education Department, Dong Thap University, Dong Thap 870000, Vietnam

6 Faculty of Chemistry, Thai Nguyen University of Education, Thai Nguyen 250000, Vietnam; hoanglh@tnue.edu.vn

7 Center for Examinations and Foreign Languages-Informatics, Ha Noi Metropolitan University, Hanoi 100000, Vietnam; vtthuy@hnmu.edu.vn

* Correspondence: trinhthao.sptn@gmail.com (T.T.T.P.); letrinh1282@gmail.com (T.L.T.T.); Tel.: +84-983-053-500 (T.T.T.P.); +84-888-556-869 (T.L.T.T.)

Citation: Le Thi Thu, H.; Tran, T.; Trinh Thi Phuong, T.; Le Thi Tuyet, T.; Le Huy, H.; Vu Thi, T. Two Decades of STEM Education Research in Middle School: A Bibliometrics Analysis in Scopus Database (2000-2020). Educ. Sci. 2021, 11, 353. https://doi.org/ 10.3390/educsci11070353

Academic Editor: Randall S. Davies

Received: 23 June 2021

Accepted: 9 July 2021

Published: 14 July 2021

Publisher's Note: MDPI stays neutral with regard to jurisdictional claims in published maps and institutional affiliations.

Copyright: (c) 2021 by the authors. Licensee MDPI, Basel, Switzerland. This article is an open access article distributed under the terms and conditions of the Creative Commons Attribution (CC BY) license (https:// creativecommons.org/licenses/by/ $4.0 /)$.

\begin{abstract}
STEM education has become important in many countries around the world. STEM education can begin while students are very young. However, earlier research has shown that one of the most important factors influencing the decision on scientific research selection is the middle school science classes. In this research, we extract database from Scopus to evaluate the scientific results of publications in the field of STEM education in middle school in the period 2000-2020. A data set of 272 academic papers was indexed to monitor the development of this field by Scopus. The results of the quantitative analysis showed that researches on STEM education in middle schools have boomed in the last 5 years, mainly in the USA. The trend of research collaboration in the field of STEM education in middle schools is not strong. The research topics are quite diverse, focusing on a number of issues: gender, engineering education, curriculum, etc. This study has some limitations, including that only data from the Scopus database were selected and manually filtered, so our analyses totally depended on the quality of the input information imported from the Scopus database.
\end{abstract}

Keywords: bibliometric; middle school; Scopus; STEM Education

\section{Introduction}

In the 21st century, the change of human life has been accompanied by the evolution of technology. Therefore, students have to be prepared for future challenges. Scientific inquiry, scientific practices and engineering practices are required to encourage students to be a citizen who can adapt to face new conditions and problems [1]. STEM education is an interdisciplinary approach to the learning process, in which principled academic concepts are integrated with real-world lessons, where students apply knowledge and skills in the fields of science, technology, engineering and mathematics to specific contexts, making connections between schools, communities, workplaces and global institutions, which is conveyed and connects students on the basis of learning through practice and oriented to solving practical problems [2-4].

In recent years, STEM education has become important in many countries around the world, and has come to be the concern of many policy makers. In many countries, a lot of discussion on STEM is provided with claims of shortage of highly skilled labour [5]. STEM education can begin while students are very young, from elementary school to high school [6]. However, earlier research has shown that among the most important factors 
influencing the decision on scientific research selection are the middle schools science classes and particularly the science teacher [7]. Therefore, the implementation of STEM education in middle schools is necessary.

There have been researches of scientific quantitative analysis of STEM education in the world with the Web of Science database [3,8-10] These researches have painted a broader picture of the formation and development of STEM education research and applications. The researches all confirm that research in STEM education is growing rapidly in this decade. From data analysis of scientific publications in this area, we can see that research on STEM education has increased strongly in recent years in developed countries and has a positive impact on skill development of students, so to meet the needs of high-skilled labour.

In this research, we want to learn more about STEM education in middle schools. For the main purpose of this study, this research is designed to answer the following questions:

RQ1. What is the general information and annual growth trends of publications related to the fields of STEM education in middle school?

RQ2. What is the international cooperation network between countries in this research field?

RQ3. Which countries, organisations, and scholars have published the most articles relevant to the studies of STEM education in middle school?

RQ4. Which source published the most papers related to the research on the field of STEM education in middle school?

RQ5. Which paper in the collection has the most impact on the community in this research area?

RQ6. What is the most important and popular research topic in this field of study?

The results from this study will paint an overall picture of STEM education in middle school research. This information may be of interest to researchers, regulators and decision makers in order to build a good vision for this field of research in the coming years.

There are five main bibliographic databases that can be used to conduct a bibliometrics analysis, including: Web of Science (WoS), Scopus, Google Scholar, Microsoft Academic and Dimentions [11]. Among them, WoS and Scopus are used the most for bibliometrics analyses. In this study, we decided to use the Scopus database as the search engine because it covers a wider range of documents than other databases [12,13].

\section{Methodology}

General science mapping workflow consists of five stages: (1) Study design; (2) Data collection; (3) Data analysis; (4) Data visualisation; and (5) Interpretation [14,15].

In the study design stage, the main research question was: What was the bibliometric of publications in STEM Education in Middle School, indexed in the Scopus database for the 2000-2020 period? Data collection stage is divided into three sub-stages: Data collection, data filtering and data cleaning.

Step 1: Data collection. The author team searched from Scopus's database (http: //www.scopus.com), with advanced search options for entering search conditions and suitable operator method by syntax of this search tool on 27 January 2021.

Keyword searching for STEM education was completed according to previous research [2]: "STEM" or a combination of words "(educat* OR learn* OR teach*) with words (science* AND technolog* AND engineer* AND mathematic*)". The character "*" represents any group of characters in Scopus data search syntax. Keywords of STEM Education are matched with "junior high school" OR "middle school". The search is limited to summary, keyword and title of document. Year of Publication is selected for the period from 2000 to 2020. Limited data about Document type is Articles and Review in the field of social sciences, written in English language.

Step 2: Data filtering. We filtered data by censoring titles, abstracts and keywords, removing materials that are not related to STEM education and materials that are not 
directly related to the research issue. Eliminated materials are often those that contain the verb "stem" or the term "stem" in the biological domain.

With these lists, we did some preliminary analysis on tools provided by Scopus provides to gather additional information about the author, affiliation and journal. Metadata of the final publication collection were exported to two different formats for postprocessing in the two most popular and effective bibliometrics analysis tools, BIB format for the Biblioshiny tool [11] and CSV format for the VOSviewer tool [16]. Additional information on the Scopus website and from the Scimago Journal \& Country Rank ( https:/ /www.scimagojr.com/) (accessed on 10 February 2021)were also used to support the analyses.

Query strings querying the data across the Scopus database and the data collected before further analysis are shown in Table 1.

Table 1. Data collection results from the Scopus database.

\begin{tabular}{|c|c|c|c|}
\hline Query Strings & Result & Filtered & Data Collected \\
\hline $\begin{array}{l}\text { TITLE-ABS-KEY-AUTH ("junior high school” OR } \\
\text { "Middle school") AND (PUBYEAR > } 2000 \text { AND } \\
\text { PUBYEAR < 2021) AND TITLE-ABS-KEY-AUTH } \\
\text { ((educat* OR learn* OR teach*) AND ((science* } \\
\text { AND technolog* AND engineer* AND } \\
\text { mathematic*) OR \{STEM\})) AND SUBJAREA } \\
\text { (soci) AND (LIMIT-TO (DOCTYPE, “ar") OR } \\
\text { LIMIT-TO (DOCTYPE, "re")) AND (LIMIT-TO } \\
\text { (LANGUAGE, "English")) }\end{array}$ & 288 & 16 & 272 \\
\hline
\end{tabular}

Step 3: Data cleaning. Downloaded data need to be cleaned because the quality of analysis greatly depends on the quality of input data. Some data errors have been corrected in this sub-stage. For example, "University of Houston- Downtown" and "University of Houston Downtown" were corrected as one affiliation; "University of Nebraska" and "University of Nebraska-Lincoln" and "University of Nebraska-lincoln" were corrected as one affiliation.

Various analytical techniques have been applied to extract information from collections of publications.

General information of the publication collection was summarised, and annual number of publications was analysed to draw the growth trend of the research field. The study period was separated into two sub-periods, 2000-2013 and 2014-2020 for comparing the development in each sub-period. Contribution by each country based on numbers of papers and citations was analysed to identify the most productive ones. The total number of research institutions publishing in the field of STEM education in middle school research was identified and the top 10 institutions based on the number of papers and citations were extracted. Core sources and the top 10 scientific journals publishing papers related to this field were identified. Additional information about the top 10 publishing journals, for instance, the number of papers and citations, Scimago scientific journal ranking, and Scopus journal quartile, were collected to have a general understanding of the quality of the published collection. Among all authors, the top 10 most productive ones based on number of publications were identified, along with their institutions and h-indexes. When doing the author affiliation statistics, we rely on key information from the author's most recent publications, because some authors have changed affiliation in recent years. Total citations of their papers in the collection and annual citations over the last five years were provided to analyse their influence on the community. VOSviewer was used to build the co-authorship network between all authors with at least four publications to generate the author collaboration network. Based on the number of citations, the top 10 most cited papers were extracted, along with the evolution of its annual citations over the last five years. 
A co-occurrence network of 71 most popular keywords based on their frequency was generated using VOSviewer tool. This network is very useful to identify important research themes in the field of STEM education in middle school. Keywords that often appeared together in published papers were coded in the same colours and grouped in the same clusters.

\section{Results}

\subsection{General Information and Growth Trend}

The most important information of the collection in the field of STEM education in middle school are shown in Table 2. Although the authors have listed the publications in the period 2000-2020, the first publications on this field appeared in 2006. In the period from 2006 to 2020, the authors published a total of 272 publications, of which the majority were Articles with 267 publications ( $98.2 \%$ ), the reviews only accounted for $1.8 \%$ of publications. The publications are published on 125 different Scopus sources.

Table 2. Main information of the publication collection.

\begin{tabular}{cc}
\hline Description & Results \\
\hline MAIN INFORMATION ABOUT DATA & \\
Timespan & $2006: 2020$ \\
Sources (Journals, Books, etc.) & 125 \\
Documents & 272 \\
Average citations per documents & 10.03 \\
DOCUMENT TYPES & 267 \\
Article & 5 \\
Review & \\
AUTHORS & 903 \\
Authors & 20 \\
Authors of single-authored documents & 883 \\
Authors of multi-authored documents & \\
AUTHORS COLLABORATION & 21 \\
Single-authored documents & 0.301 \\
Documents per Author & 3.32 \\
Authors per Document & 3.76 \\
Co-Authors per Documents & \\
\hline
\end{tabular}

A total of 903 authors have appeared in the collection of 272 publications, (equivalent to 3.32 Authors per Document), in which the number of Authors of multi-authored documents accounts for the majority of the collection with $883(97.8 \%)$; the ratio of CoAuthors per Documents is 3.76. The number of Authors of single-authored documents accounted for only a ratio of $2.2 \%$ ( 20 scholars). These scholars have published a total of 21 Single-authored documents in the collection ( $7.7 \%$ of the publications).

Information on annual volume of publications and cumulative citations is shown in Figure 1. Annual growth rate of researches on STEM education in middle school is $33.48 \%$. The growth trend of scientific output related to STEM education in middle school can be divided into two periods: 2006-2015 and 2016-2020. The first stage saw a very low volume, with a total of 61 publications (22.4\%) over a 10-year period, and an annual volume of publishing lower than 20 publications. In the second stage (the last 5 years), the number of researches on this topic boomed, and 211 publications were published (accounting for $77.6 \%$ of the whole collection).

The number of citations has increased steadily every year, rapidly increasing in recent years, which corresponds with the increase in the number of researches on this topic. At the time of this research, the total number of citations recorded from the Scopus database was 2727 , equivalent to 10.03 citations per document. The collection's h-index is 26 , which means there are 26 publications with at least 26 citations. 


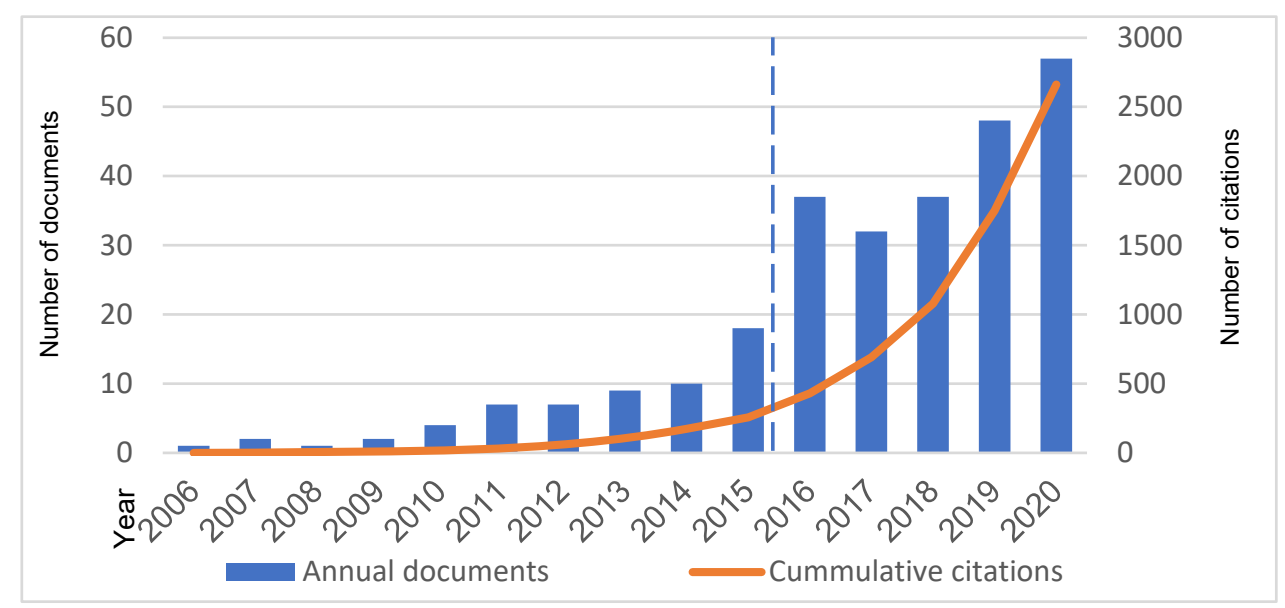

Figure 1. Bar chat illustrates annual number of publications and its cumulative citations.

Statistics of the number of citations of publications related to research on STEM education in middle school are shown in Table 3. The number of articles that have not been cited from any document is $67(24.6 \%)$, and there are 144 articles with citations from 1 to $10(52.9 \%)$. The number of articles with more than 55 citations is $10(3.7 \%)$, of which only 3 articles have over 100 citations.

Table 3. Number of citations of the publication collection.

\begin{tabular}{ccc}
\hline Number of Citations & Number of Documents & Percentage \\
\hline$>100$ & 3 & $1.1 \%$ \\
55 to 100 & 7 & $2.6 \%$ \\
21 to 54 & 28 & $10.3 \%$ \\
11 to 20 & 23 & $8.5 \%$ \\
1 to 10 & 144 & $52.9 \%$ \\
0 & 67 & $24.6 \%$ \\
\hline
\end{tabular}

\subsection{Contribution by Countries}

Information on the top 10 countries with the highest number of publications related to the field of STEM education in middle school is shown in Table 4. It can be seen that the majority of publications is contributed by authors from the US with more than three quarters of the collection (208 papers, $76.5 \%$ ). The remaining countries on this list contribute much less than the country in first rank: Turkey: 18 papers (6.6\%), Australia and Canada: $9(3.3 \%)$, respectively; six countries placed at the bottom of the rank with three to seven articles: Taiwan, Indonesia, Israel, South Korea, Vietnam, and the United Kingdom. Note that the total percentages of these countries exceed $100 \%$ because a given article may have co-authors from different countries.

Table 4. The top 10 countries with the highest number of publications.

\begin{tabular}{cccccc}
\hline Rank & Country/Territory & No. of Papers & $\mathbf{\%}$ & No. of Citations & $\mathbf{\%}$ \\
\hline 1 & United States & 208 & $76.5 \%$ & 2296 & $84.2 \%$ \\
2 & Turkey & 18 & $6.6 \%$ & 43 & $1.6 \%$ \\
3 & Australia & 9 & $3.3 \%$ & 122 & $4.5 \%$ \\
4 & Canada & 9 & $3.3 \%$ & 85 & $3.1 \%$ \\
5 & Taiwan & 7 & $2.6 \%$ & 66 & $2.4 \%$ \\
6 & Indonesia & 6 & $2.2 \%$ & 61 & $2.2 \%$ \\
7 & Israel & 5 & $1.8 \%$ & 52 & $1.9 \%$ \\
8 & South Korea & 4 & $1.5 \%$ & 20 & $0.7 \%$ \\
9 & Vietnam & 3 & $1.1 \%$ & 7 & $0.3 \%$ \\
10 & United Kingdom & 3 & $1.1 \%$ & 5 & $0.2 \%$ \\
\hline
\end{tabular}


In terms of total citations by country, the US is still the country with the largest number of citations with 2296 citations (equivalent to $84.2 \%$ ), followed by Australia with 122 citations $(4.5 \%)$ and Canada with 85 citations (3.1\%). The remaining countries have a number of citations from 5 to 66 .

\subsection{Contribution by Institutions}

According to the retrieved Scopus database, the collection of 272 papers was published by a total of 613 different affiliations. The top 10 most productive institutions based on the number of publications are shown in Table 5 . As can be seen, all affiliations on this list come from the United States. Coming in at first rank is Purdue University with 21 papers (7.7\%), triple the affiliations in second rank, the University of Minnesota Twin Cities, followed by the University of Pittsburgh with six papers. The remaining Institutions have four to five papers that have been published. Remarkably, Vanderbilt University has only 5 papers but has outstanding citations of $368(13.5 \%)$. This is because this Institution contributed the two articles with the highest number of citations in the collection: [17] with 188 citations and [18] with 137 citations. The University of Nebraska-Lincoln also has a fairly high total citations with only 5 papers due to the contribution of the top 2 citations, including [19] with 111 citations and [20] with 72 citations.

Table 5. Top 10 most productive institutions publishing based on total number of publications.

\begin{tabular}{|c|c|c|c|c|}
\hline Order & Institution & Country & No. of Articles & No. of Citations \\
\hline 1 & Purdue University & United States & 21 & 173 \\
\hline 2 & University of Minnesota Twin Cities & United States & 7 & 80 \\
\hline 3 & University of Pittsburgh & United States & 6 & 62 \\
\hline 4 & Vanderbilt University & United States & 5 & 368 \\
\hline 5 & University of Nebraska-Lincoln & United States & 5 & 199 \\
\hline 6 & Clemson University & United States & 5 & 74 \\
\hline 7 & Virginia Polytechnic Institute and State University & United States & 5 & 60 \\
\hline 8 & College of Science & United States & 4 & 91 \\
\hline 9 & Georgia Institute of Technology & United States & 4 & 30 \\
\hline 10 & University of Georgia & United States & 4 & 24 \\
\hline
\end{tabular}

International cooperation network (at least two papers) in the field of STEM education in middle school is shown in Figure 2. The size of the nodes indicates the number of publications, while the thickness of the lines between nodes shows the strength of collaboration. According to data from Scopus database, there are 39 countries with authors participating in the research on and publication of this field. However, international cooperation to carry out research is not much, mainly the US cooperation with other countries such as Turkey, Australia, Israel, Spain, Canada and South Korea.

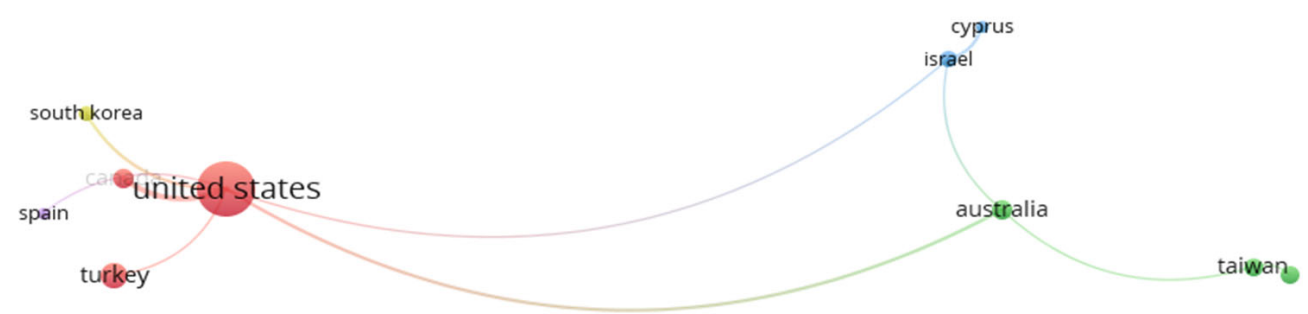

Figure 2. International cooperation network in the field of STEM education in middle school. Artwork generated with VOSviewer. 
The cooperation between institutions in the STEM education in middle school is shown in Figure 3. Similar to Figure 2, the size of the points indicates the publication number of each institution, while the thickness of lines between the points shows the strength of the cooperation, the link is drawn when there is cooperation between two institutions with at least two papers. It can be seen that research cooperation in this field is not much. The figure specifies four groups of affiliations with their cooperation. However, collaborations in research on the topic mainly stem from groups of authors working in two or four affiliations.

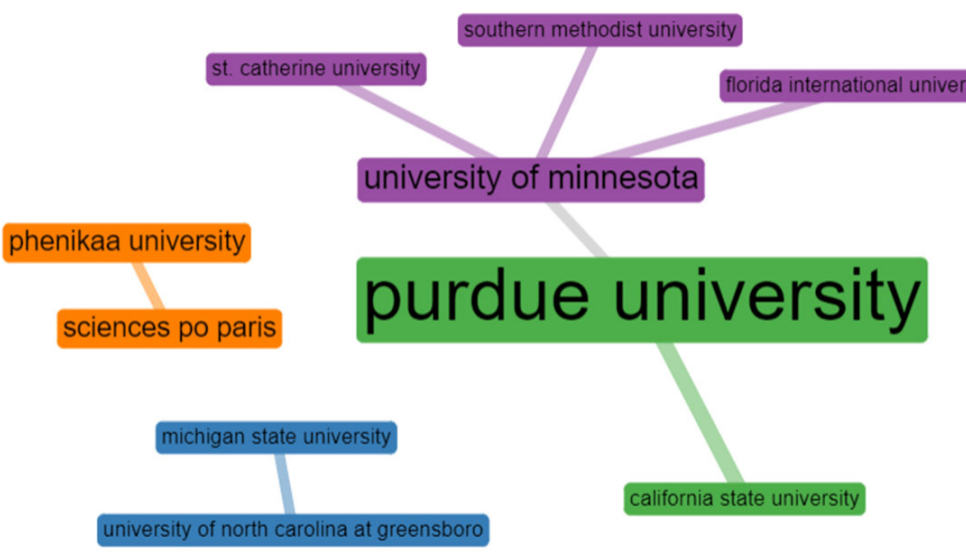

Figure 3. Cooperation between affiliations in the field of STEM education in middle school. Artwork generated by Biblioshiny.

\subsection{Contribution by Journals}

As shown in Table 2, the collection of 272 papers were published in 125 difference sources, and the top 15 most active journals publishing papers related to field of STEM education in middle school is shown in Table 6. Accordingly, these 15 journals have published 109 papers, accounting for $40.1 \%$ of the collection with the number of citations of 1240 , equivalent to $45.1 \%$ of the total number of citations. Journal of Science Education and Technology (JSET) has the largest number of papers published on this topic with 16 papers, 206 citations; followed by International Journal of STEM Education (IJSTEME) with 12 papers, 141 citations; The next two ranks on this list have nine articles on this topic: Journal of Chemical Education (JCE) (with 79 citations) and Journal of Women and Minorities in Science and Engineering (JWMSE) (21 citations). In the fifth rank, Technology and Design Education (IJTDE) has 8 papers, 46 citations. The next three ranks have seven papers and have quite similar citations: Research in Science Education (RSE): 121; International Journal of Science and Mathematics Education (IJSME): 109; International Journal of Science Education (IJSE): 93.

Most of these journals are ranked highly in the journal rankings of Scopus: Q1 (9), Q2 (4). Only one journal ranked Q3 and one journal ranked Q4, being the Middle School Journal, which has only recently been indexed in the Scopus database in 2019. Ranked by CiteScore, Computers and Education is a journal with the highest indicators (12.7); this journal is ranked \# 3/1254 in the Education field of Scopus. The second rank is JRST journal with CiteScore 7.2 rating \# 18/1254. The third rank is JSET journal with CiteScore 5.2 , ranking \# 53/1254.

These journals come from eight different publishers: Springer Nature (6), Taylor \& Francis (2), American Chemical Society (1), Begell House (1), Elsevier (1), Purdue University Press (1), ISRES Publishing (1), Wiley-Blackwell (1) and Modestum Ltd. (1). 
Table 6. Top 15 most active journals publishing research related to the field of STEM education in Middle school based on total number of publications.

\begin{tabular}{|c|c|c|c|c|c|c|c|}
\hline Order & Source & $\begin{array}{l}\text { Publishing } \\
\text { House }\end{array}$ & $\begin{array}{l}\text { No. of } \\
\text { Articles }\end{array}$ & $\begin{array}{l}\text { No. of } \\
\text { Citations }\end{array}$ & $\begin{array}{l}\text { Scopus } \\
\text { Quartile }^{\text {a }}\end{array}$ & $\begin{array}{l}\text { CiteScore } \\
2019^{\mathrm{a}}\end{array}$ & $\begin{array}{l}\text { Journal Impact } \\
\text { Factor }{ }^{b}\end{array}$ \\
\hline 1 & $\begin{array}{c}\text { Journal of Science Education and } \\
\text { Technology(JSET) }\end{array}$ & $\begin{array}{l}\text { Springer } \\
\text { Nature }\end{array}$ & 16 & 206 & Q1 & 5.2 & 1.644 \\
\hline 2 & $\begin{array}{c}\text { International Journal of STEM } \\
\text { Education(IJSTEME) }\end{array}$ & $\begin{array}{l}\text { Springer } \\
\text { Nature }\end{array}$ & 12 & 141 & Q1 & 3.0 & 1.850 \\
\hline 3 & $\begin{array}{c}\text { Journal of Chemical } \\
\text { Education(JCE) }\end{array}$ & $\begin{array}{l}\text { American } \\
\text { Chemical } \\
\text { Society }\end{array}$ & 9 & 79 & Q2 & 3.4 & 1.385 \\
\hline 4 & $\begin{array}{c}\text { Journal of Women and Minorities } \\
\text { in Science and } \\
\text { Engineering(JWMSE) }\end{array}$ & $\begin{array}{l}\text { Begell } \\
\text { House }\end{array}$ & 9 & 21 & Q2 & 1.5 & - \\
\hline 5 & $\begin{array}{l}\text { International Journal of Technology } \\
\text { and Design Education(IJTDE) }\end{array}$ & $\begin{array}{l}\text { Springer } \\
\text { Nature }\end{array}$ & 8 & 46 & Q1 & 3.0 & 1.326 \\
\hline 6 & $\begin{array}{l}\text { Research in Science } \\
\text { Education(RSE) }\end{array}$ & $\begin{array}{l}\text { Springer } \\
\text { Nature }\end{array}$ & 7 & 121 & Q2 & 3.2 & 1.578 \\
\hline 7 & $\begin{array}{c}\text { International Journal of Science } \\
\text { and Mathematics } \\
\text { Education(IJSME) }\end{array}$ & $\begin{array}{l}\text { Springer } \\
\text { Nature }\end{array}$ & 7 & 109 & Q1 & 3.1 & 1.485 \\
\hline 8 & $\begin{array}{c}\text { International Journal of Science } \\
\text { Education(IJSE) }\end{array}$ & $\begin{array}{l}\text { Taylor \& } \\
\text { Francis }\end{array}$ & 7 & 93 & Q1 & 2.8 & 2.248 \\
\hline 9 & Computers and Education & Elsevier & 6 & 172 & Q1 & 12.7 & - \\
\hline 10 & Middle School Journal & $\begin{array}{l}\text { Taylor \& } \\
\text { Francis }\end{array}$ & 6 & 2 & Q4 & 0.5 & - \\
\hline 11 & $\begin{array}{c}\text { Journal Of Pre College Engineering } \\
\text { Education Research(JPEER) }\end{array}$ & $\begin{array}{l}\text { Purdue } \\
\text { University } \\
\text { Press }\end{array}$ & 5 & 26 & Q1 & 2.6 & - \\
\hline 12 & $\begin{array}{l}\text { International Journal Of Education } \\
\text { In Mathematics Science And } \\
\text { Technology(IJEMST) }\end{array}$ & $\begin{array}{l}\text { ISRES } \\
\text { Publishing }\end{array}$ & 5 & 18 & Q3 & 1.1 & - \\
\hline 13 & $\begin{array}{c}\text { Journal Of Research In Science } \\
\text { Teaching (JRST) }\end{array}$ & $\begin{array}{l}\text { Wiley- } \\
\text { Blackwell }\end{array}$ & 4 & 123 & Q1 & 7.2 & 3.870 \\
\hline 14 & $\begin{array}{c}\text { Eurasia Journal Of Mathematics } \\
\text { Science And Technology Education } \\
\text { (EJMSTE) }\end{array}$ & $\begin{array}{l}\text { Modestum } \\
\text { Ltd. }\end{array}$ & 4 & 49 & Q2 & 3 & - \\
\hline 15 & $\begin{array}{c}\text { Cultural Studies Of Science } \\
\text { Education (CSSE) }\end{array}$ & $\begin{array}{l}\text { Springer } \\
\text { Nature }\end{array}$ & 4 & 34 & Q1 & 1.8 & 0.437 \\
\hline
\end{tabular}

a: As per data Scimago Journal \& Country Rank on 10 February 2021 (https:/ /www.scimagojr.com); ${ }^{\text {b }}$ : As per The Clarivate Analytics Impact Factor on 11 February 2021 (https:// clarivate.com).

Bibliographic coupling among these top 15 journals is illustrated in Figure 4, showing two different groups. The first group includes nine journals: JSET, IJSTEME, IJSME, IJTDE, JSTE, JPEER, EJMSTE, Computers and Education, and Middle School Journal. The second group includes the six remaining journals: JCE, JWMSE, RSE, CSSE, JRST, and IJSE.

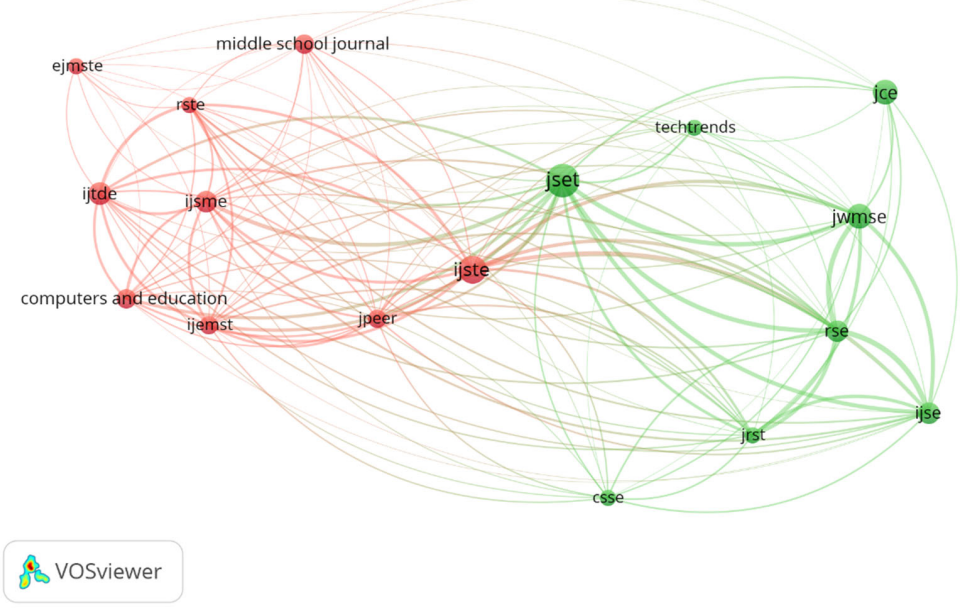

Figure 4. Bibliographic coupling among the most active journals publishing research related to the field of STEM education in middle school. Artwork generated by VOSviewer. 


\subsection{Contribution by Authors}

The top 10 most productive authors based on number of publications, their citations and h-indexes are shown in Table 7. All of these authors come from institutions of the United States. The number of articles by the top authors is not too different, and not too high, with only 3-6 articles; the authors' h-indexes (only for the papers in the collection under the research) are quite similar, only 2-3. Moore, T.J. of Purdue University is in the first rank with 6 papers and 45 citations, the authors in the next two ranks respectively have 5 papers, namely, Herro, D. from Clemson University, and Roehrig, G.H. from University of Minnesota Twin Cities. There are two authors in the fourth rank with four papers: Guzey, S.S. from Purdue University, and Quigley, C. from University of Pittsburgh. The remaining authors on the list have three papers on the subject of STEM education in middle school, of which there are two representatives of University of Nebraska at Omaha with the highest number of citations being Nugent, G. (186 citations), and Grandgenett, N. (183 citations); these two authors are co-authors of two papers with a high number of citations: [19] - 111 citations, and [20] -72 citations. Tan, E. from the University of North Carolina at Greensboro also has third ranked citations with 105 citations (of which there are 91 citations in the paper [21] up to the time the research is performed).The remaining two authors are Dare, E.A. from Florida International University with 27 citations, and Bottia, M.C. from the University of North Carolina at Charlotte with 20 citations.

Table 7. Top 10 most productive authors related to the field of STEM education in Middle school based on total number of publications.

\begin{tabular}{|c|c|c|c|c|c|c|}
\hline Rank & Author & Institution & Country & No. of Articles & No. of Citations & H-Index \\
\hline 1 & Moore, T.J. & Purdue University & United States & 6 & 45 & 3 \\
\hline 2 & Herro, D. & Clemson University & United States & 5 & 73 & 3 \\
\hline 2 & Roehrig, G.H. & University of Minnesota & United States & 5 & 27 & 2 \\
\hline 4 & Guzey, S.S. & Purdue University & United States & 4 & 57 & 3 \\
\hline 4 & Quigley, C. & University of Pittsburgh & United States & 4 & 40 & 2 \\
\hline 5 & Nugent, G. & $\begin{array}{l}\text { University of Nebraska } \\
\text { at Omaha }\end{array}$ & United States & 3 & 186 & 3 \\
\hline 5 & Grandgenet, $\mathrm{N}$. & $\begin{array}{l}\text { University of Nebraska } \\
\text { at Omaha }\end{array}$ & United States & 3 & 183 & 2 \\
\hline 5 & Tan, E. & $\begin{array}{l}\text { The University of North } \\
\text { Carolina at Greensboro }\end{array}$ & United States & 3 & 105 & 2 \\
\hline 5 & Dare, E.A. & Florida International University & United States & 3 & 27 & 2 \\
\hline 5 & Bottia, M.C. & $\begin{array}{l}\text { The University of North } \\
\text { Carolina at Charlotte }\end{array}$ & United States & 3 & 20 & 2 \\
\hline
\end{tabular}

Annual publications and citations of the top 10 authors can be seen in Figure 5. Nugent, G., and Grandgenett, N., who are co-authors of two of the three articles on the topic [19,20], cooperate. The author Tan, E. also has a first publication from a very early time [21]. These are 3 of the top 10 authors that have publications in the first sub-period (2006-2015). Among the remaining authors, Moore, T.J., Herro, D. and Quigley, C. have continuous publications from 2016 to 2019.

The co-authorship network of 15 scholars with at least three publications related to the field of STEM education in middle school is shown in Figure 6. Authors are represented by nodes. The size of the nodes indicates the number of publications, while the thickness of the lines between nodes shows the strength of collaboration (meaning number of publications of which they were co-authors). It can be seen that the cooperation between scholars to research on this topic is not strong, mainly performed in small groups of two to four scholars. These groups do not have much cooperation with each other. It is shown that there are six groups of authors in the figure. 


\section{Top-Authors' Production over the Time}

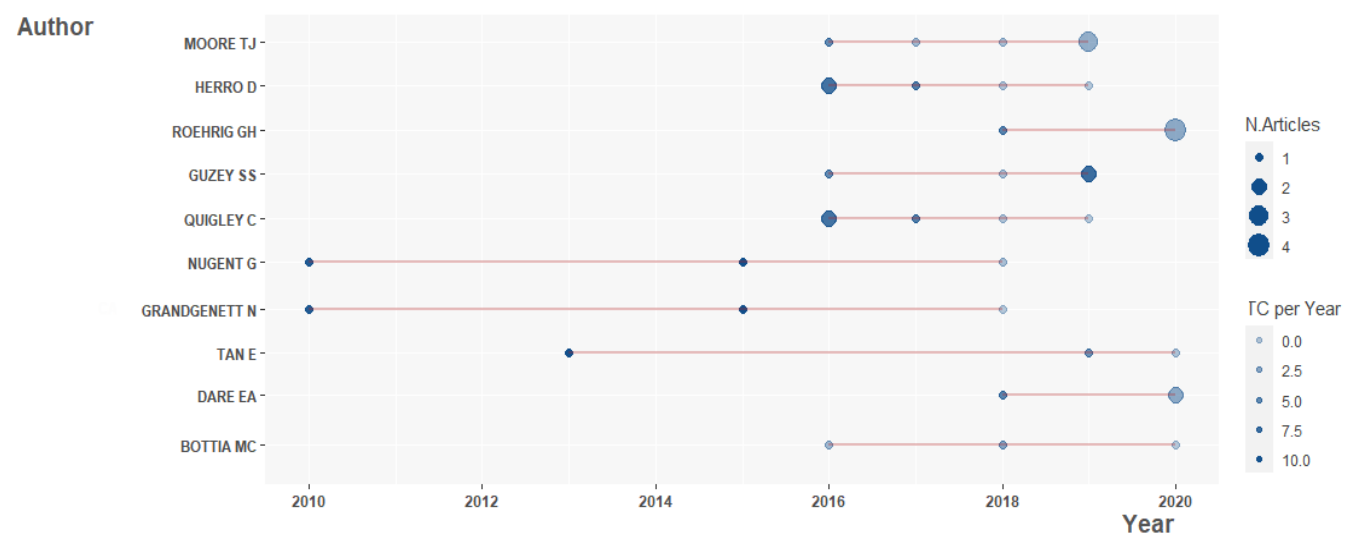

Figure 5. Annual publications of the top 10 most productive authors over the time.

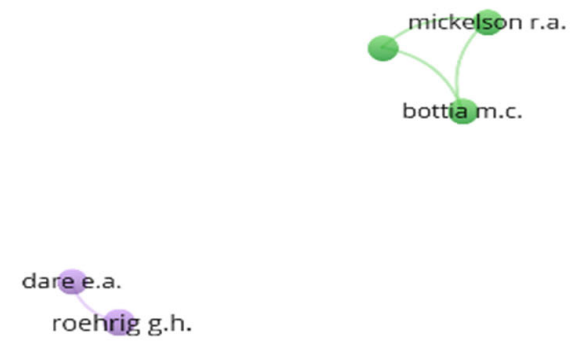

grandgenett $\mathrm{n}$.

nugent $\mathrm{g}$.

quigley $c$.

herro $\mathrm{d}$.

\& E Vosviewer
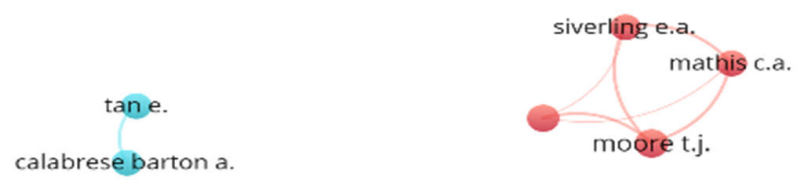

Figure 6. Co-authorship network of 15 scholars with at least three publications.

\subsection{The Most Influential Articles}

The list of the top 10 most cited papers in the published collection of 272 papers is shown in Table 8, along with their numbers of citations over the last five years. The total number of citations of the top 10 papers is 936 , which corresponds to $34.3 \%$ of the total citations of the collection at the time of this study (2727 citations). The number of citations of these papers in the last 5 years has mostly increased rapidly in recent years. Eight out of ten papers in the top 10 were conducted and published with the first author from the United States. The article about integrating computational thinking with K-12 science education using agent-based computation ranked first, with 188 citations [17]. The main author of the paper is from University of Calgary, Canada. Ranked second in the list is a research on how to enhance learning and engagement through embodied interaction within a mixed reality simulation, with 137 citations [18]. Only one paper is a single-authored document (English, 2017); the author of this article is from Queensland University of Technology, Australia. 
Table 8. Overview of the top 10 most cited papers in the publication collection.

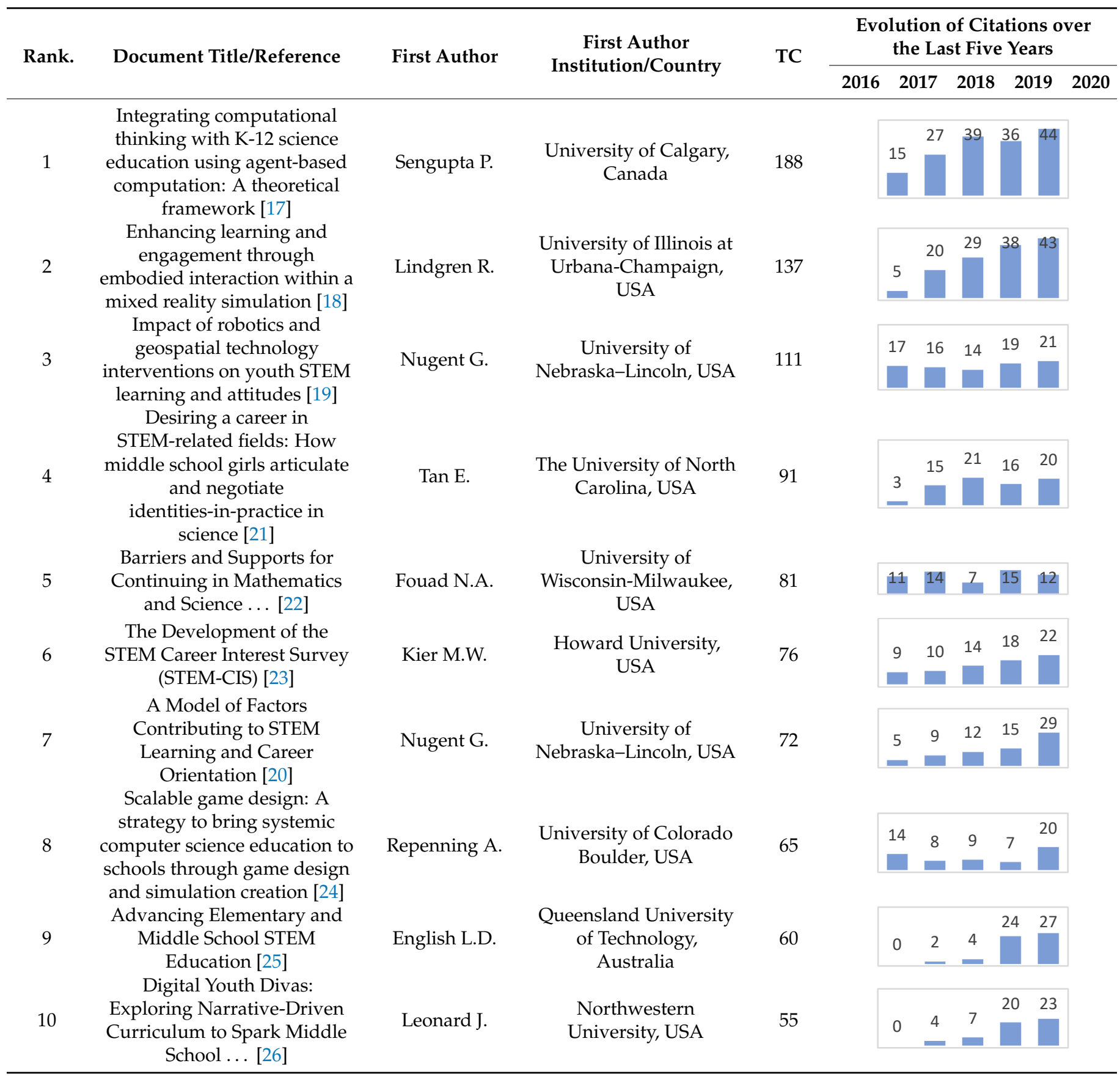

\subsection{Keywords and Terms Analysis}

The co-occurrence network of 70 most popular keywords, which appeared at least three times, is presented in Figure 7. Each keyword is represented by a node, and the thickness of lines between two nodes is proportional to the strength of the relationship between them. This relationship was determined by the number of times they appeared together in published papers of the published collection. Close and related keywords (or research topics) were coded in the same colours and grouped in the same clusters. The keywords are grouped into five clusters with four most concentrated groups: The red group has keywords related to research on STEM in gender including main keywords: gender, science, informal education, motivation, technology. The green group includes key curriculum keywords: curriculum, engineering education, teaching, design. The blue group includes keywords related to programming in STEM education: professional aspects, 
robotics, education computing, programming. The yellow group includes some keywords: science education, engineering design, STEM integration.

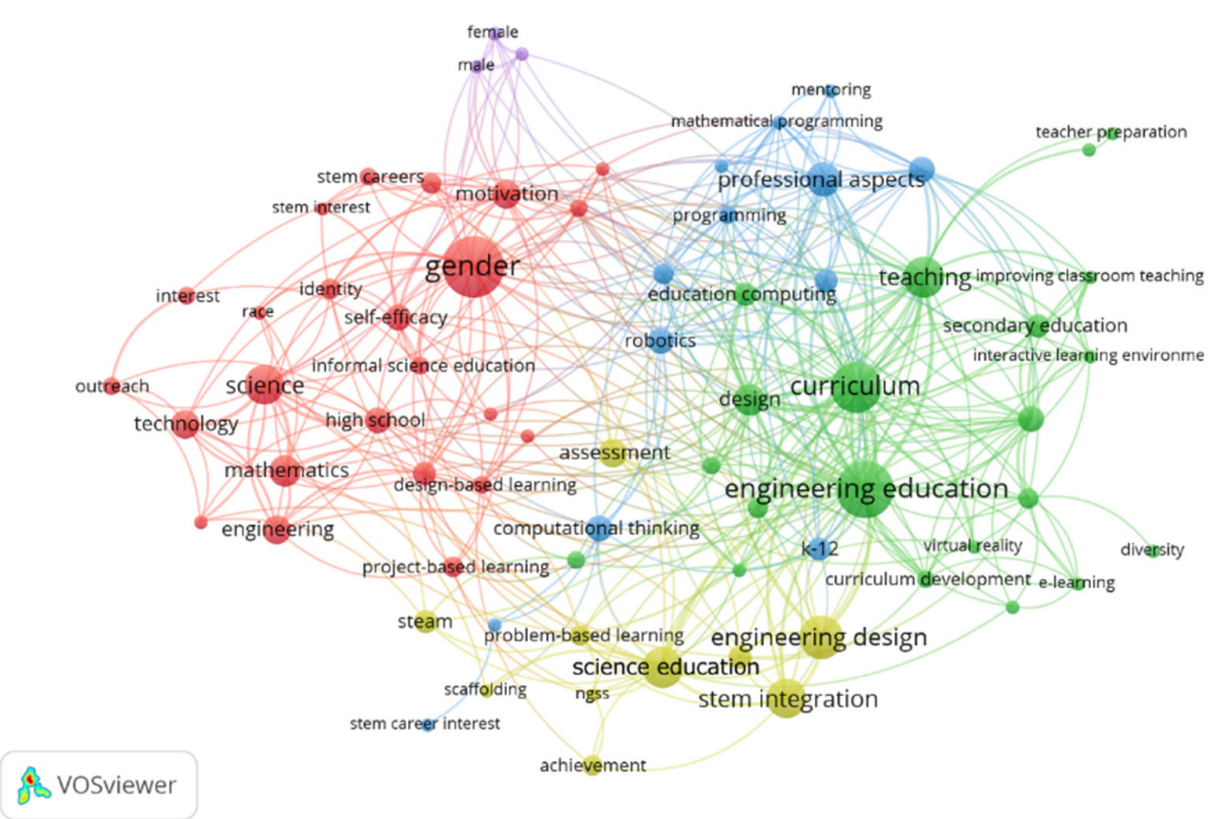

Figure 7. Co-occurrence network of 71 most popular keywords (at least three times). Artwork generated by VOSviewer.

\section{Discussion}

In this study, bibliographic data in the Scopus database have been utilised to draw the overall picture of all publications studying and discussing about STEM education in middle school during the last two decades (2000-2020). The studies on STEM education in middle schools have skyrocketed in the last five years; therefore, there is no regional parity, focusing mainly on the USA. The number of citations has increased steadily every year, rapidly increased in recent years, commiserating with the increase in the number of studies on this topic.

The first study on STEM education in middle schools was in 2006, with the first publication of the groups of authors such as Karen F. White and Mara H. Wasburn from Purdue University, USA; however, the publication received no interest from researchers in the same field as no citations have been documented [27]. There was a relatively low number of publications in this field between 2006 and 2015, with a total of 61 publications over 10 years (only accounting for $22.4 \%$ of the number of publications in the two decades). In the second period (the last 5 years), the number of studies on this topic skyrocketed, with 211 publications (accounting for $77.6 \%$ of the entire collection) (see Figure 1). This trend is also reflected in the studies of the 10 authors with the highest number of publications where 7 out of 10 authors on this list have only had publications in the last 5 years (see Figure 5).

The studies in these two decades are mainly published by authors and research groups from the USA with $76.5 \%$ of the number of publications. The United States is also the country with the most total citations with 2296 citations (equivalent to $84.2 \%$ ) (see Figure 2). There is not much international cooperation to carry out studies; it is mainly the US cooperation with other countries (see Figure 3). Accordingly, it can be said that the USA plays an important role in establishing and continuing scientific relations between countries. The role of the United States is also confirmed in most of this study data on the top 10 most productive institutions publishing list (see Table 5), the top 10 most productive authors list (see Table 7), and the top 10 most cited papers list (see Table 8). This is also consistent with previous studies when analysing the output of publications in STEM education in general in the world [3]. Besides this, it can be said that the USA is driving research to be done in 
the field of STEM education in middle school. Meanwhile, in previous studies on STEM in general, the UK is the country that tends to lead research in this topic. This suggests that the USA may have a strategy in focusing research on STEM education.

The trend of research cooperation in the field of STEM education in middle school is not strong when only recognising the cooperation between four groups of affiliations (see Figure 3) and six subgroups of scholars (from two to four scholars) while these groups are not related each other (see Figure 5).

When analysing the sources of the publications, the authors found that the researchers tended to publish in the journals that ranked high in the journal rankings of Scopus (see Table 5), 9/10 journals in the top 10 most active journals are ranked Q1 and Q2. This also demonstrates the quality of research in the field.

Data on the top 10 authors on the number of publications in this field shows that the research on the field of STEM education in middle school is a research direction among their many research directions, the number of publications by these authors was not too different and not high (3-6 articles). Although the number of publications is not high, some authors have much higher total citations than others because they contribute to articles with a relatively high number of citations: Nugent, G. (186 citations), Grandgenett, N. (183 citations), Tan, E. (105 citations) (see Table 7).

The publications with the greatest impact in this area have tended to increase the number of citations in recent years (see Table 8), which can be explained by the sudden increase in the number of publications announced in the last 5-year period.

The keyword analysis in Figure 7 shows that the research topics are diverse, focusing on several issues: gender, engineering education, curriculum, professional aspects, science education, etc. These issues are divided into four main groups that are all related to each other.

\section{Conclusions}

This study uses bibliographic data from the Scopus database to study the development of publications related to the field of STEM education in middle school published over the past two decades. The main findings of the study are: 1 . The number of publications has increased steadily, especially in the period 2016-2020; along with the increase in the number of published studies, the number of citations has also increased rapidly during this period. 2. The United States is the country with the greatest influence in this research field; the affiliations and authors have the greatest impact almost all from this country. 3. The research cooperation in this area is not strong; the cooperation between countries is mainly from the United States and some other countries: Turkey, Australia, Israel, Spain, Canada and South Korea. The study acknowledges the cooperation between four groups of affiliations (2-4 institutions) and six groups of authors. 4 . The quality of the publications in the field is relatively high when many of the publications are published in journals with high-ranking indexes.

\section{Limitations}

This study has been limited by some limitations which were already reported in previous papers $[2,13]$. First, using only bibliographic data from the Scopus database might not include all publications in the literature related to the field of STEM education in middle school. Second, the authors tried to manually filter all irrelevant papers in different Scopus categories; however, this filtering might not be perfect and omissions might occur. Third, some types of information are not standardised in the Scopus database, for example, author names and author institutions. As manual correction is not possible, this might affect to our results as our analyses totally depended on quality of the input information imported from the Scopus database. Fourth, some types of analyses, for instance, statistic of scholars by genders, cannot be done in this study due to technical limitations of the Biblioshiny and VOSviewer tools. Advantages of other bibliographic analysing tools, such 
as SciMAT [28] combining with bibliographic information from other databases, should be investigated to optimise this type of research in the future.

Author Contributions: The paper has been conceptualised, discussed, written and revised jointly by all the authors. All authors have read and agreed to the published version of the manuscript.

Funding: This research was funded by the Thai Nguyen University of Education (TNUE) under grant number CS.2020.08.

Institutional Review Board Statement: Not applicable.

Informed Consent Statement: Not applicable.

Data Availability Statement: Not applicable.

Acknowledgments: The authors would like to thank the developers of the VOSviewer tool, Nees Jan van Eck and Ludo Waltman, and the developers of the Biblishiny tool, Massimo Aria and Corrado Cuccurollo, for developing these software for data processing and data visualisation of this study.

Conflicts of Interest: The authors declare no conflict of interest.

\section{References}

1. Bybee, R. The Case for STEM Education: Challenges and Opportunities; NSTA Press: Arlington, VA, USA, 2015.

2. Thao, T.T.P.; Ha, C.T.; Trung, N.T.; Huong, L.T.T.; Van Dinh, N.; Trung, T. A Bibliometric Review of Research on STEM Education in ASEAN: Science Mapping the Literature in Scopus Database, 2000 to 2019. Eurasia J. Math. Sci. Technol. Educ. 2020, 16, em1889. [CrossRef]

3. Özkaya, A. Bibliometric Analysis of the Publications Made in STEM Education Area. Bartın Üniv. Ĕ̈it. Fakültesi Derg. 2019, 8, 590-628. [CrossRef]

4. Legewie, J.; DiPrete, T.A. The High School Environment and the Gender Gap in Science and Engineering. Sociol. Educ. 2014, 87, 259-280. [CrossRef]

5. Hsu, Y.-S.; Fang, S.-C. Opportunities and Challenges of STEM Education. In Asia-Pacific STEM Teaching Practices; Springer: Berlin/Heidelberg, Germany, 2019; pp. 1-16.

6. Riera, B.; Emprin, F.; Annebicque, D.; Colas, M.; Vigário, B. HOME I/O: A virtual house for control and STEM education from middle schools to Universities. IFAC PapersOnLine 2016, 49, 168-173. [CrossRef]

7. Venville, G.; Rennie, L.; Hanbury, C.; Longnecker, N. Scientists Reflect on Why They Chose to Study Science. Res. Sci. Educ. 2013, 43, 2207-2233. [CrossRef]

8. Uğuz, A.P.; Aksoy, A.P.; Oral, A.P. The Analysis of Conceptual Development of Stem Education by Bibliometry. J. Educ. Instr. Stud. World 2017, 7, 118-128.

9. Batdi, V.; Talan, T.; Semerci, Ç. Meta-Analytic and Meta-Thematic Analysis. Int. J. Educ. Math. Sci. Technol. 2019, 7, 382-399.

10. Yu, Y.-C.; Chang, S.-H.; Yu, L.-C. An Academic Trend in STEM Education from Bibliometric and Co-Citation Method. Int. J. Inf. Educ. Technol. 2016, 6, 113-116. [CrossRef]

11. Moral-Muñoz, J.A.; Herrera-Viedma, E.; Santisteban-Espejo, A.; Cobo, M.J. Software tools for conducting bibliometric analysis in science: An up-to-date review. El Prof. Inf. 2020, 29, 1-20. [CrossRef]

12. Mongeon, P.; Paul-Hus, A. The journal coverage of Web of Science and Scopus: A comparative analysis. Scientometrics 2016, 106, 213-228. [CrossRef]

13. Pham-Duc, B.; Tran, T.; Trinh, T.-P.-T.; Nguyen, T.-T.; Nguyen, N.-T.; Le, H.-T.-T. A spike in the scientific output on social sciences in Vietnam for recent three years: Evidence from bibliometric analysis in Scopus database (2000-2019). J. Inf. Sci. 2020. [CrossRef]

14. Börner, K.; Chen, C.; Boyack, K.W. Visualizing knowledge domains. Annu. Rev. Inf. Sci. Technol. 2005, 37, 179-255. [CrossRef]

15. Zupic, I.; Čater, T. Bibliometric methods in management and organization. Organ. Res. Methods 2014, 18, 429-472. [CrossRef]

16. Van Eck, N.J.; Waltman, L. Software survey: VOSviewer, a computer program for bibliometric mapping. Scientometrics 2010, 84, 523-538. [CrossRef] [PubMed]

17. Sengupta, P.; Kinnebrew, J.S.; Basu, S.; Biswas, G.; Clark, D. Integrating computational thinking with K-12 science education using agent-based computation: A theoretical framework. Educ. Inf. Technol. 2013, 18, 351-380. [CrossRef]

18. Lindgren, R.; Tscholl, M.; Wang, S.; Johnson, E. Enhancing learning and engagement through embodied interaction within a mixed reality simulation. Comput. Educ. 2016, 95, 174-187. [CrossRef]

19. Nugent, G.; Barker, B.; Grandgenett, N.; Adamchuk, V.I. Impact of Robotics and Geospatial Technology Interventions on Youth STEM Learning and Attitudes. J. Res. Technol. Educ. 2010, 42, 391-408. [CrossRef]

20. Nugent, G.; Barker, B.; Welch, G.; Grandgenett, N.; Wu, C.; Nelson, C. A Model of Factors Contributing to STEM Learning and Career Orientation. Int. J. Sci. Educ. 2015, 37, 1067-1088. [CrossRef]

21. Tan, E.; Barton, A.C.; Kang, H.; O’Neill, T. Desiring a career in STEM-related fields: How middle school girls articulate and negotiate identities-in-practice in science. J. Res. Sci. Teach. 2013, 50, 1143-1179. [CrossRef] 
22. Fouad, N.A.; Hackett, G.; Smith, P.L.; Kantamneni, N.; Fitzpatrick, M.; Haag, S.; Spencer, D. Barriers and Supports for Continuing in Mathematics and Science: Gender and Educational Level Differences. J. Vocat. Behav. 2010, 77, 361-373. [CrossRef]

23. Kier, M.W.; Blanchard, M.R.; Osborne, J.W.; Albert, J.L. The Development of the STEM Career Interest Survey (STEM-CIS). Res. Sci. Educ. 2013, 44, 461-481. [CrossRef]

24. Repenning, A.; Webb, D.C.; Koh, K.H.; Nickerson, H.; Miller, S.B.; Brand, C.; Horses, I.H.M.; Basawapatna, A.; Gluck, F.; Grover R.; et al. Scalable Game Design. ACM Trans. Comput. Educ. 2015, 15, 1-31. [CrossRef]

25. English, L.D. Advancing Elementary and Middle School STEM Education. Int. J. Sci. Math. Educ. 2017, 15, 5-24. [CrossRef]

26. Pinkard, N.; Erete, S.; Martin, C.K.; de Royston, M.M. Digital Youth Divas: Exploring Narrative-Driven Curriculum to Spark Middle School Girls' Interest in Computational Activities. J. Learn. Sci. 2017, 26, 477-516. [CrossRef]

27. White, K.F.; Wasburn, M.H. CareerQuesting: Evaluating Web-Based Resources for Interesting Girls in STEM Careers. Int. J. Inf. Commun. Technol. Educ. 2006, 2, 45-59. [CrossRef]

28. Cobo, M.J.; Lopez-Herrera, A.G.; Herrera-Viedma, E.; Herrera, F. SciMAT: A new science mapping analysis software tool. J. Am. Soc. Inf. Sci. Technol. 2012, 63, 1609-1630. [CrossRef] 